Mr Clovis Delor Mbeudeu'

The Institute of International and

Comparative Education

Zhejiang Normal University

Jinhua City, Zhejiang Province

China
Original scientific paper

UDC: 37.022

DOI: $10.17810 / 2015.100$

\title{
LINGUISTIC TOLERANCE IN THE PROCESS OF INTERNATIONALIZATION OF CHINA HIGHER EDUCATION IN THE NEW ERA
}

\begin{abstract}
This paper contends that China higher education has become one of the most attractive academic hubs for citizens of developing and developed nations. Empirical evidences show that the opening up policy and the spread of Confucius institutes in the world support China higher education breakthrough. More importantly linguistic tolerance that is practiced during the selection process of international students and officials to undertake short or long exchange programs in Chinese institutions may account for the rapid internationalization of China higher education. The researcher has used content analysis of grants and scholarship offers to Chinese universities, related policy papers and statements to discover that the Chinese government gives a place of choice to students and workers of developing countries through the medium of many English-taught programs at bachelor's, master's and doctoral levels. In addition, the researcher has used the interview to collect some data from scholarship awardees. This was done in a bid to find out their impressions about English language requirements to be fulfilled by candidates for the award of various scholarships and short training programs in Chinese universities. The analysis of interviewees' verbatim strongly supports the claim that China higher education attracts more talents thanks to more tolerant and flexible linguistic requirements applied during the selection process. Owing to this new vision of higher education in China, it is recommended that more top ranking universities in the West, which use English as foreign or second language, must emulate China example and offer more flexible linguistic requirements for Englishtaught programs to talents from developing nations. This will undoubtedly foster academic mobility and inclusive development of the world in this new era.
\end{abstract}

Keywords: higher education, opening up policy, linguistic tolerance, New English, new era, internationalization.

\section{Introduction}

China higher education has been on the spotlight for the past two decades. The establishment, at the beginning of the $21^{\text {st }}$ century, of the Forum on China-Africa Cooperation (FOCAC, hereafter) has further strengthened exchanges between China and Africa. Indeed, many observers and researchers have stressed that China has attracted and will continue to attract more and more talents and government officials to its universities for several reasons

'mbeuclovis@gmail.com 
(MOFCOM, 2018). Some of these reasons include the economic might of China, its technological and infrastructural advancements and its opening up policy. The latter is so dear to president $\mathrm{Xi}$ who is following Deng Xiaoping's vision of a new China with a shared future for mankind. Another reason that has also been traced in the literature is the spread of the cultural and ideological stance of China through the rapid expansion of Confucius centers across the globe not forgetting the quality of education provided across China educational system (OECD, 2010). The last reason that tends to be neglected and which is believed to have attracted more talents to Chinese universities is the language policy that is applied by China during the selection of talents to come study in China. Through students' mobility, the internationalization of higher education has grown from leaps to bound and the number of students abroad "has been multiplied by a factor of 4 between 1975 and 2008" (Beine, Noel, \& Ragot, 2014). These international students do not only apply for programs offered in universities in the US, the UK, Germany, France, but also in some developing countries like Cuba, India, South Africa, and China. The literature underlines that there is a growing number of students who enroll in Chinese universities for different programs (Bodomo, 2014). Alongside Chinese-taught programs, Chinese universities have recently embarked on offering more and more English-taught programs for developing and developed countries. Some of the programs are directed to students and workers of African countries which share relation ties with China. The award of entry into Chinese universities is unique in its kind in the world: selection criteria are more inclusive than selective and the key point is at the level of the language of instruction for the program that is offered. The objective of this paper is to critically assess language requirements policy during the selection process into Chinese universities. Specifically, the paper focuses on linguistic tolerance which is the biggest stance upon which Chinese internationalization of higher education is couched. In a bid to achieve the purpose of this paper, the following parts will be reviewed. First, the researcher focuses on an overview of Chinese universities. Then he moves to the language requirements policy in China higher education, the selection criteria as concerns language of instruction. The researcher will later focus on the analysis of some documents and verbatim in order to see how China unique experience can inspire other universities in the world to design more flexible language requirements during the selection process to foster academic mobility and inclusive development of the world in this new era.

\section{Overview of Chinese universities and programs offered}

Many provincial-level universities and national key universities in China offer various long and short-term programs to students and government officials across the world and specifically from developing countries. During their academic stay in Chinese institutions of higher learning, selected candidates acquire information, knowledge, skills, and expertise from lecturers and classmates. Selected candidates from developing countries, in turn, will share and exchange their ideas, knowledge, skills, and experiences with them (Gonondo, 2017). To effectively carry out various programs in Chinese universities, different state organs have put in place a series of enabling factors, which facilitate the running of different programs offered. In this connection, Chinese universities offer a wide range of programs with two medium of expression. Indeed, students and officials from developing countries can apply for English-taught or Chinese-taught programs. During the fifth FOCAC, some African states and China committed themselves to collaborate in a new partnership based on knowledge sharing and ideas exchange. Such initiatives are being realized through the "transfer of advanced and applicable technologies", the sharing of "experience in the development of science parks", and the conduct of "joint research programs" (FOCAC, 2012). Interestingly, it is laudable to see 
that the programs which are offered in universities that host international students range from teaching Chinese to speakers of other languages, business Chinese, Chinese Law, International Relations, Preschool Education, Studies of Higher Education, Comparative Education without forgetting innovative programs in computer engineering, medicine, civil engineering and others (MOFCOM, 2018). These programs offer 4-year bachelor programs and graduate school programs in each of the chosen domains. Apart from these academic programs for international students, it is worth mentioning Sino-African teacher education cooperation, which consists of short-term training course programs for African teachers. Such programs are offered in Chinese universities and facilitated by the Ministry of Commerce (MOFCOM), and the UNESCO-China Funds-in-Trust Project (CFIT). Theses exchange programs; it should be pointed out, are implemented within the framework of Belt and Road Initiative and aim to promote the people-to-people and cultural exchanges. The literature offers some insights on the ever-increasing number of international students in Chinese province level and national key universities. According to the Ministry of Commerce PRC, starting from 2008 a number of 1,695 students from developing countries attended programs under the Chinese government scholarship scheme. Out of this number of international students, 835 of them have graduated with master degrees. Many observers have often questioned the result of this increase. While some say that the government is trying to translate its opening up policy and various FOCAC resolutions into action, others think China's selection process into its universities, for the time being, remains one of the most flexible about English language proficiency requirements. Though the call for 2017-2019 applications into the Master on comparative education at Zhejiang Normal University (ZJNU, hereafter) requires applicants to provide a Test of English as Foreign Language (TOEFL) or International English Language Testing System certificate (IELTS), the author observed that an overwhelming majority of scholarship awardees were selected for the program without showing any proof of their language proficiency test as required (for more on this, see MOFCOM, 2018). Far beyond this, he has realized that more talents are attracted to Chinese universities thanks to the linguistic policy behind China's selection process into universities, which is, in his opinion way too flexible and tolerant. From this observation, the following query can be put forward: How may the linguistic tolerance practiced by Chinese universities account for the ever-increasing number of international students in universities across mainland China?

\section{The language policy in China higher education}

The language of instruction in an institution of higher learning is a pre requisite for a successful selection process that is inclusive and promising for international students who do not always share the same language of instruction back home. This is also true of an inclusive selection process and the cement of an effective internationalization of higher education in the world in a bid to ensure students" mobility and give the possibility to talents to freely move abroad and follow programs in English without necessarily having good grades in language proficiency tests. In an attempt to accompany the vision of inclusive development by President $\mathrm{Xi}$, Chinese university authorities take language issues seriously when it comes to admitting international students; especially from developing countries. In an attempt to grasp the Chinese language policy at higher education, it is important to consider the national language policy put in place by the central government.

China's multiethnic characteristic has prompted the central government to be so cautious when it comes to choosing a language that will act as a unifying factor for all Chinese citizens including minority groups. Despite the fact that English has been threatening Mandarin in 
China, the latter remains the only official language across mainland China. This can be seen through this extensive excerpt from article 12 of the Education Law of the People's Republic of China:

"The Chinese language, both oral and written, shall be the basic oral and written language for education in schools and other educational institutions. Schools or other educational institutions which mainly consist of students from ethnic minority groups may use in education the language of the respective ethnic community or the native language commonly adopted in that region. Schools and other educational institutions shall in their educational activities popularize the nationally common spoken Chinese and the standard written characters" (Education Law of PRC, 1995).

Despite the strong language policy, which advocates the sole use of the Chinese language for nationals, so many efforts to promote English and many other languages remain a force to reckon with. The results are visible within the Chinese society that is gradually opening up to the diplomatic world. Despite the promotion of so many languages none of them has been awarded the status of official language although the central government, via the Ministry of Education, has set up a strong language teaching policy from pre-primary and primary education to tertiary education. At tertiary level of education, the promotion of foreign languages is translated through the boom of colleges of foreign languages in different universities across mainland China and beyond. The languages promoted at colleges of foreign languages at ZJNU include, French, Japanese, Korean, Spanish, German, Russian, and English to name but these few. Despite the promotion of these languages, none of them has been given the status of an official language despite the opening up policy that is so dear to the Chinese government. The fact that English is not an official language may raise some issues as concerns the Chinese government decision to offer both Chinese and English-taught programs to international students and government officials. China has been hosting and will keep on hosting more and more international students. The latter come from French-speaking nations, Arabic-speaking countries, Spanish and Portuguese-speaking countries that share bilateral relations with the country (Ministry of Education, 2018). Some of these countries may have English as their official language. This notwithstanding, when we look deeply into the linguistic background of such countries they do not always use English as a medium of instruction across the school curriculum but as a subject in some schools either state or private-owned. Because of this, one may have thought that for a student from such countries to study in China, they ought to take language proficiency test in English before being admitted in Chinese universities that offer English-taught programs for international students (see for example the MOFCOM 2017-2019 call for application into the Master on comparative education program). This has not always been the case recently when overseas students apply for English-taught programs. It is in this vein that in this paper the author opines that linguistic tolerance is a key factor during the selection process into Chinese universities. Considering all these facts, how are language issues handled by Chinese universities when they select new international students, visiting scholars, and government officials to come study in China or for exchange programs?

\section{The selection criteria as concerns language of instruction}

The Chinese experience has a lot to offer as concerns language policy in Chinese universities that host international students and government officials from different linguistic and cultural backgrounds. Before we delve into the language selection criteria that support admission into 
Chinese universities it is important to differentiate between the possibilities that are offered to applicants. There are candidates who apply for English-taught programs and those who apply for Chinese-taught programs (MOFCOM, 2017). Prospective candidates can apply for partially supported, fully funded or self-sponsored programs depending on their majors and the programs available in universities that host international students. As concerns the Chinese-taught programs, the language policy is flexible as the applicant is required to show some basic proficiency in Chinese by holding a HSK 2, 3 or 4 obtained in a Confucius institute or center in their country of origin. With this working knowledge, the applicant is accepted for a Chinese-taught program but prior to embarking on this program, he or she must take a oneyear language training during which he or she must repeat and complete an HSK 4 or ideally a level 5 HSK. This opportunity offered to international students is a unique one as most of the applicants would work extremely hard and complete the various HSK levels requested by the scholarship requirements. Through this linguistic flexibility, many international students are now taking courses in teaching Chinese, and in many other fields of studies ranging from mechanical engineering, civil engineering, computer sciences, medicine, and agriculture to name only these few.

Onto the linguistic flexibility as concerns English medium education for international students and government officials from developing and developed countries in some Chinese universities, there is a success story that must be told to the world in a bid to explain the increasing number of international students studying in China. A close look at fully funded, partially funded, and self- sponsored scholarship offers to study in prestigious Chinese universities has it that linguistic tolerance has been guiding the selection process. In fact, most if not all scholarship offers for English-taught programs care less about the presentation of a recognized and standardized language proficiency proof like what is required in other universities in the West and the US. In these western settings where there are native speakers of English as opposed to a country like China or India where New Englishes have prospered with a staggering number of Extended Circle users of English linguistic flexibility is not exercised (Kachru, 1986; Jenkins, 2002). Although a language proficiency proof is required from applicants, there are many international students right now in China whose secondary education or undergraduate education was completed in a national or official language, which is not English. The practice of this linguistic tolerance is the most important criterion that has enabled many talents to register and study in Chinese universities that offer programs in English. This is a good example China is showing the world; the ability to allow more talents to come study in China in a language they may not be so proficient in. Language requirements flexibility during the selection process of international students into Chinese institutions of higher learning may be understood from different perspectives.

First, that Chinese universities apply flexible linguistic requirements for English-taught programs may be regarded as a great move to stress the prestige of Mandarin as the only official language while English remains a language under promotion. From this stance, English in China is like a lingua franca as it serves communication purposes for people who come to China because of the opening up policy. This is because when people meet they need a contact language that is shared by the majority to complete daily transactions and facilitate intelligibility.

Second, since English is not an official language in China the Chinese government has thought it wise not to impose a TOEFL or IELTS certificate on international students who plan to study in China. This decision not to compel students to sit for these standardized English tests is 
simply because if China does so it will be promoting the Anglo Saxon culture through the study of English. It is common knowledge that language is culture and the opening up of China to the world today is translated through some linguistic and cultural imperialism via the establishment of different Confucius institutes and centers. The promotion of Mandarin in various Confucius centers across the globe is a real testimony that China has really embarked on the spread of its language and culture. In this connection, during the selection process to study any English-taught program in Chinese universities it is always recommended to applicants to register in a Confucius institute to learn some basic Chinese.

Third, from an economic point of view if Chinese universities compel students to sit for these English standardized tests, the funds generated will in no way contribute to the Chinese economy but to the countries that own these tests. For instance the fee that is paid for taking HSK comes to boost the Chinese economy but if China requests applicants to sit for IELTS and TOEFL the fees will instead be directed to boost the economy of the UK and the US that hold the exclusive rights of the language proficiency tests.

Onto another point of view, China practices linguistic tolerance because when English is the language of instruction for a program it only serves international students during their academic stay in China. This is because when they return home, they may not use English to share the competences they must have acquired in Chinese universities. It is the case with many students from French-speaking countries in Africa, Spanish-speaking countries in Latin America/Africa, Portuguese-speaking nations where the working language in the administration is not English. In this case it is a wise decision to allow international students, government officials, and visiting scholars from developing countries to study or undertake short-term training in Chinese universities without necessarily showing a good mastery of English language. That way, upon return home the beneficiaries will be able to use their national or official languages other than English to share their Chinese experiences and build their countries as well. Once more this linguistic tolerance is a solid foundation for the internationalization of Chinese higher education and the strengthening of the opening up policy under implementation in China new era.

\section{Analyzing the Chinese experience and drawing some benefits for other countries}

Since the opening up of higher education in China to international students and government officials from developing countries, many talents have been attracted to China. Moreover, these talents are given the opportunity to study in China top-ranking provincial or national key institutions of higher learning. The ever-growing number of international students to Chinese universities has called for many waves of criticisms amongst higher education specialists. While some say China internationalization of higher education is to further strengthen its cultural ties with sister nations, others believe that China is set to give a new direction to the internationalization of higher education in the world higher education map (see for instance OECD, 2013; Times World Universities Ranking which places China 3 universities among the world top 50 universities). Still, some critics voice that Chinese internationalization of education is not a model that is worth emulating because the products that are accepted and that study in China are not always the best; they are second or even third-class applicants who must have failed to get admission into European or US-based institutions.

The Chinese experience nowadays stands tall and bold in the midst of the US and the western way of internationalizing higher education. China today more than yesterday is an academic 
destination for most, if not, all developing countries with an ever growing number of young students and workforce. The latter needs training in science, technology, engineering and mathematics so as to foster development in their countries of origin. Also, these developing countries need more trained youths in entrepreneurship, civil engineering, computer engineering, e-commerce, big data management, biomedical sciences, to name but these few (FOCAC, 2018). The wide range of these training opportunities has prompted Chinese authorities to design a win-win internationalization of higher education which is deeply rooted in their long standing tradition of inclusive development of the world translated by a shared future for mankind. This holistic approach to higher education internationalization is based on linguistic tolerance for countries whose language of instruction is not English but whose young citizens need to be well trained to develop their various countries upon return home. This is what has made China a real academic partner for most developing nations. The fact that students can study in Chinese universities without being compelled to take the TOEFL or IELTS standardized tests as it is the case for some countries where English is not a mother tongue is a unique experience for the applicants to be trained in a country that has become a super power. The boom of the Chinese economy directs the new order of the world. When an economy is booming there are many reasons behind it. One of these reasons is definitely the education system from primary to tertiary education. The latter must be highly competitive allying both research and teaching without forgetting lifelong learning and the offer of innovative programs. In a bid to allow other countries that have cooperation ties with China, it was high time the country opened up its higher education and made access criteria more flexible and realistic while keeping in mind the spread of the Chinese dream and the total promotion of Chinese cultural and linguistic values.

Beneficiaries of scholarship programs for master-taught programs in various fields at Chinese universities acknowledge, in their immense majority, the impact of linguistic tolerance they have experienced during their academic stay in the host universities. During my 9-month stay at Zhejiang Normal University, I came across so many talented international students who fall under one of the following categories of scholarship schemes: fully-funded scholarships, government scholarships, provincial scholarships, partially-funded scholarships. During my interactions with these students, a good majority of them first acknowledged that when they were applying for the program they were sure that the language barrier will prevent them from succeeding. The students who applied for English-taught programs and others for Chinese-taught programs experienced some linguistic tolerance, as they were able to manage their training in English when they could not express their ideas in a more acceptable way in Chinese for those who applied for Chinese-taught programs. A case in point is a Cameroonian $\mathrm{PhD}$ candidate whose program was in Chinese but who could not manage academic Chinese with ease but during pre-defenses, and even the final defense members of the panels who were all Chinese allowed him to present his work in English. Another illustration is a typical case that I experienced during pre-defenses whereby linguistic tolerance of various lecturers gave the opportunity to many international students from countries like Laos, India, Guinea Bissau and Sri Lanka to present their work in rather simple, yet intelligible English. Through these examples, China has opened a new highway for the internationalization of education. This new highway, I think, is the new order of reshaping the future of the internationalization of higher education. Indeed, there are many lessons that can be drawn from these cases that do not remain isolated to Zhejiang Normal University.

First, the lesson China is teaching the world today is that no matter where a talent comes from he or she must not be prevented from excelling for the so-called sake of language proficiency 
test results. Many students right now after completing their studies in China have become proficient in their research language register; something that was not possible before their enrolment. To corroborate this idea, three students from the 2016 batch of comparative education acknowledged that before they came to China, they could not sustain any conversation in English; talk less of writing an academic paper but today they can confidently chair meetings, and present papers to an English-speaking audience. Another student from the 2017 class whose first language is French and who is from Cameroon also recognizes that it is only China that can give the opportunity to talents to come and learn from the Chinese experience regardless of the first language used in their country of origin. The student added that if China were not linguistically tolerant, many international students would never be selected into prestigious universities across mainland China.

Second, the lesson we can learn is that China emphasizes skills and competences when it comes to being trained rather than language accuracy. In fact, allowing international students to study in English-taught programs and government officials to attend short-term programs without an authentic proof of language proficiency is a true indicator that what makes an economy prosperous is not the ability to be linguistically correct but to be able to use the knowledge and competences acquired to develop one's nation.

Third, the linguistic policy that outlines admission of international students into Chinese universities is supported by the idea that it may be clumsy to deny access to talents into a program because of a language test that is not part of the host country's linguistic and cultural heritage. This goes in hand with the national language policy of China that has never made English an official language alongside Mandarin but instead encourages the promotion of English, which has become today a contact language in China because of the country opening up policy. By also promoting English as a language of the world, China has been able so far to maintain the linguistic hegemony of mandarin, which has been suffering some threats from the world lingua franca: English.

As can be seen from the foregoing, China internationalization of higher education is on the right track as more and more international students and government officials from developing countries are admitted irrespective of their linguistic proficiency in English. The linguistic flexibility and tolerance that characterizes the selection process can be the key to the successful story of China internationalization of higher education. With such language proficiency requirements tolerance many developing countries' citizens have been admitted in Chinese key universities. The Chinese government through this act has also benefited so much as these citizens who are trained have become a new crop of ambassadors who will act as crusaders of the Chinese ideology once they return back home. It remains crystal clear that other universities in the West ought to comply with Chinese ways of internationalizing higher education by applying more flexible language proficiency requirements. This way, academic mobility and inclusive development of the world in the new era will significantly be boosted and technological gaps among nations will be narrowed. 


\section{References}

Beine, M., Noel, R., \& Ragot, L. (2014). The determinants of international mobility of students, Economics of Education review, 41 (2014), 40-54.

Bodomo, A. (2014). Africans in China: The Experience from Education and Training Africans in China: The Experiences from Education and Training. Beijing.

FOCAC. (2012). The Fifth Ministerial Conference of the Forum on China-Africa Cooperation Beijing Action Plan (2013-2015). Retrieved August 8, 2018, from /www.focac.org

FOCAC. (2018). The 2018 Beijing Summit of the Forum on China-Africa Cooperation, Beijing Declaration - Towards an Even Stronger China-Africa Community with a Shared Future. Retrieved November 15, 2018, from http://www.focac2018.com/en/669.shtml.

Gonondo, J. (2017). Africa and China higher education cooperation: establishing knowledge Sharing partnership between students. Journal of Education and Practice, 8 (2017). Retrieved from www.iiste.org on August 8, 2018.

Jenkins, J. (2002). “A Sociolinguistically Based, Empirically Researched Pronunciation Syllabus for English as an International Language".Applied Linguistics, 23 (1), (83-103).

Kachru, B.B. (1986). The Alchemy of English. The Spread, Functions and Models of Non-native. Englishes. Oxford: Pergamon Press.

Ministry of Commerce, PRC. (2018). Academic Education Programs Sponsored by the Ministry Of Commerce, PRC. Retrieved May 10, 2018 from www.mofcom.gov.cn/article/iliyjl/k/201805/20180502738929.shtml

Ministry of Education, PRC. (1995). Education Law of the People's Republic of China. Retrieved November 30, 2018, from www.MOE.PRC.

OECD. ( 2013). PISA 2012 results in focus: what 15-year-olds know and what they can do with What they know. Retrieved May 05, 2018, from www.pisa.oecd.org

OECD. (2010). PISA 2009 Results: What students know and can do - student performance in reading, mathematics and science. Retrieved December 20, 2017, from

https://www.oecd.org>pisa>pisaproducts.

\section{Acknowledgments}

My appreciations go to our lecturers at Zhejiang Normal University and all Chinese institutions that supported me. I express my heartfelt gratitude to Dr Zhang Yuting who encouraged all foreign students to have their term papers published in academic journals. I am also grateful to my supervisor, Dr Jessica Xiao Hong TIAN for going through the first manuscript of this paper. I finally thanked the Ministry of Commerce, People's Republic of China for supporting my stay in China to take the master program on Comparative Education.

\section{Biographical note:}

Clovis Delor Mbeudeu is a holder of a second level postgraduate teacher's diploma - DIPES II in English Language and Literatures in English from the Higher Teachers Training College (ENS) Yaounde. He has been teaching English as a Foreign Language for 10 years now. Besides, he holds a master degree in English Didactics from the University of Yaounde 1, Cameroon and another master degree in Comparative Education from Zhejiang Normal University, China. He is an active member of the Cameroon English Language and Literature 
Teachers Association - CAMELTA - where he has been a workshop facilitator for the past 10 years at national pedagogic conferences. His fields of interest include; comparative education, translation and TEFL, designing and running mobile communities of practices, integrating ICTs in teaching and learning EFL, professional development and supervision of English instruction. 